\title{
ĐÁNH GIÁ KẾT QUẢ ĐIỀU TRI PHẪU THUẬT SEO HẸP KHÍ PHẾ QUẢN DO LAO
}

\author{
Trương Thanh Thiết*, Nguyễn Hữu Lân*, Nguyễn Hoài Nam**
}

TÓM TẮT

Đặt vấn đề: Tại Việt Nam, chúng tôi ghi nhận số công trình nghiên cứu về hẹp khí phế quản (KPQ) do lao còn han chế. Việc chẩn đoán vị trí, mức độ, chiều dài đoan hẹp và các tổn thương kèm theo trong bênh hẹp KPQ do lao là điều hết sức quan trọng và đóng vai trò quyết đinh cho các chỉ định điều trị phẫu thuật. Đối tượng và phương pháp: Nghiên cứu tiến cứu mô tả hàng loạt ca trên 48 bệnh nhân hẹp KPQ do lao đưỡc điều trị bằng phẫu thuật tạo hình KPQ tại Khoa phẩu thuật lồng ngực, BV Pham Ngọc Thạch từ 01/01/2015 đến 31/12/2018. Kểt quả: 48 BN hẹp KPQ bao gồm: 03 BN hep khí quản đoan $1 / 3$ giữa, 09 BN hẹp phế quản gốc phải, $36 \mathrm{BN}$ hẹp phế quản gốc trái. Nhóm BN hep phế quản gốc (PQG), chúng tôi ghi nhân nữ chiếm đa số $91,1 \%$ và tuổi trung bình là 30,7 tuổi. Phương pháp phẫu thuâat gồm $40 \%$ cắt nối $\mathrm{KPQ}$ đơn thuân và $60 \%$ cắt thùy kèm cắt nối $K P Q$. Tỉ lệ biến chứng sớm sau mổ là $28,9 \%$, rò khí kéo dài thường gặp nhất 13,3\%. Không tử vong trong và sau mổ. Theo dõi sau 12 tháng, tỉ lệ tái hẹp miệng nối là $8,9 \%$. Kết luận: Mặc dù có vài biến chứng, phẫu thuật tạo hình sẹo hẹp khí phế quản do lao có kết quả sớm và trung hạn tốt.

Tư khóa: Lao nội phế quản, hẹp khí phế quản do lao, tạo hình khí phế quản

\section{SUMMARY}

\section{EVALUATED THE RESULTS OF SURGICAL TREATMENT IN TUBERCULOUS TRACHEOBRONCHIAL STENOSIS}

Introduction: In Vietnam, we recognize that the number of studies on tuberculous tracheobronchial stenosis is limited. Diagnosis of the location, lenght and associated lesions in tuberculosis stenosis is very important for surgical treatment indications. Subjects and methods: Prospective a series of cases on 48 patients with tuberculous tracheobronchial stenosis treated plastic surgery at the Department of Thoracic Surgery, Pham Ngoc Thach Hospital in the period from 01/01/2015 to 31/12/2018. Results: 48 patients included: 03 patients with tracheal stenosis of the middle $1 / 3,09$ patients with right main bronchial stenosis, 36 patients with left main bronchial stenosis. In the group of patients with bronchial stenosis, we recorded the majority of women accounted for $91.1 \%$ and the mean age was 30.7 years. The modes of operations were sleeve resection of the main bronchus

*Bệnh viện Phạm Ngọc Thạch TPHCM

** Dai hoc Y Dướ TPHCM

Chịu trách nhiệm chính: Trương Thanh Thiết

Email: thietpnt@gmail.com

Ngày nhận bài: 8/1/2021

Ngày phản biên khoa học: 30/1/2021

Ngày duyệt bài: 27/2/2021
(40\%) and sleeve lobectomy (60\%). The rate of early postoperative complications was $28,9 \%$, the most common prolonged air leakage accounted for $13.3 \%$. No death during and after surgery. After 12 months, the rate of recurrent stenosis is $8.9 \%$. Conclusion: Although there are some complications, the early and mild term results of sugical tuberculous tracheobronchial stenosis are good.

Keywords: Endobronchial tuberculosis, tuberculous tracheobronchial stenosis.

\section{I. ĐĂT VẤN ĐỀ}

Hẹp khí phế quản (KPQ) do lao được mô tả đâu tiên vào năm 1698 bởi Richard Morton, một bác sĩ người Anh. Mặc dù bệnh lao phổi đã có sự giảm đi với sự ra đời của thuốc kháng lao hiệu quả, nhưng hẹp $\mathrm{KPQ}$ do lao vẫn tiếp tục được ghi nhận và thường bị chẩn đoán nhâm với những bệnh hô hấp khác [1]. Hẹp KPQ nặng gây ra các biến chứng ở phổi như viêm phổi, xẹp phổi, giãn phế quản, và thậm chí tử vong do suy hô hấp và ngạt thở[2]. Bển cạnh sự phát triển mạnh mẽ trong những năm gần đây của nội soi phế quản (NSPQ) can thiệp như đốt điện, đốt laser, áp lạnh trị liệu, nong KPQ và đặt Stent, phẫu thuật tạo hình KPQ đã được chấp nhận như là một trong những phương thức tốt nhất để điều trị hẹp KPQ do lao [1]. Tạo hình KPQ đạt được đâu tiến bởi Bigger vào năm 1932, từ đó hàng loạt các kỹ thuật mới được áp dụng trong nhiều bệnh KPQ khác nhau từ những tổn thương lành tính cho đến ác tính bởi nhiều phẫu thuật viên trên thế giới [3]. Trên thế giới hiện nay số lượng công trình nghiên cứu về điêuu trị hẹp KPQ do lao còn tương đối ít. Riêng tại Việt Nam, chúng tôi ghi nhận số công trình nghiên cứu vế hẹp KPQ do lao còn hạn chế. Các số liệu báo cáo còn ít và thiếu khuyết phân theo dõi lâu dài sau mổ, chính vì vậy chúng tôi thực hiện nghiên cứu này nhằm đánh giá kết quả điêu trị phẫu thuật cắt nối đoạn hẹp KPQ do lao tại Bệnh viện Phạm Ngọc Thạch thành phố Hồ Chí Minh.

\section{II. ĐỐI TƯỢNG VÀ PHƯƠNG PHÁP NGHIÊN CỨU}

2.1. Đối tượng: 48 bệnh nhân hẹp KPQ do lao được điều trị bằng phẫu thuật tạo hình cắt nối KPQ tại Khoa phẫu thuật lồng ngực, BV Phạm Ngọc Thạch trong thời gian từ 01/01/2015 đến 31/12/2018.

2.2. Phương pháp: Nghiên cứu tiến cứu mô tả hàng loạt ca. 
Phẫu thuật viên (PTV) và Bác sĩ gây mê (BSGM) dựa vào vị trí hẹp trên chụp CLVT ngực và NSPQ để quyết định đường mổ và phương pháp gây mê.

Đường mổ ngang cổ 4-6 cm cách hõm ức 2 $3 \mathrm{~cm}$ cho những phẫu thuật hẹp KQ $1 / 3$ trên và $1 / 3$ giữa, có thể kèm theo mở xương ức bán phần với đường rạch da dọc giữa xương ức cho những hẹp KQ $1 / 3$ dưới. Gây mê ống nội KQ trên đoạn hẹp (hẹp $1 / 3$ giữa hay $1 / 3$ dưới) hay ống nội KQ trẻ em đặt qua dưới đoạn hẹp (hẹp $1 / 3$ trên). Đường mở ngực phải sau bển từ 12 $15 \mathrm{~cm}$ vào khoang màng phổi liên sườn 5 cho những hẹp phế quản gốc (PQG) phải. Gây mê nội phế quản trái bằng ống 2 nòng.

Đường mở ngực trái sau bên khoảng 12 $15 \mathrm{~cm}$ vào khoang màng phổi liên sườn 5 cho những hẹp phế quản gốc trái. Gây mê nội phế quản phải bằng ống thông 2 nòng.

Các kiểu tạo hình gồm: cắt nối KQ tận - tận, cắt nối $P Q G$ tận - tận, cắt nối $P Q G$ vào Carina hay $K Q$, cắt thùy cộng cắt nối phế quản thùy vào KQ hoặc Carina hoặc PQG.

Bênh nhận được theo dõi ít nhất 12 tháng sau mổ. Biến kết cục chính của nghiên cứu là tỉ lệ tái hẹp của $\mathrm{BN}$ sau thời gian theo dõi. Tái hẹp đoạn nối $\mathrm{KPQ}$ được xác định bằng chụp CLVT dựng hình cây KPQ và NSPQ có hẹp. Các biến phụ khác được đánh giá bao gồm: Chỉ số Kanofsky (tính bằng\%), mức đô khó thở, chức năng hô hấp, lâm sàng, nhập viện lại do biến chứng và xử lý biến chứng. Các số liệu được xử lý bằng phần mềm SPSS 20.0.

\section{KẾT QUẢ NGHIÊN CứU}

Qua thời gian nghiên cứu từ tháng 01 năm 2015 đến tháng 12 năm 2018, có 48 BN hẹp $\mathrm{KPQ}$ do lao đủ tiêu chuẩn để đưa vào nghiên cứu tại khoa Ngoại lồng ngực, Bệnh viện Phạm Ngọc Thạch. Bao gồm:

- 03 BN hẹp KQ đoạn 1/3 giữa

- 09 BN hẹp phế quản gốc phải

- 36 BN hẹp phế quản gốc trái.

Chúng tôi ghi nhận 03 TH hẹ KQ đoạn $1 / 3$ giữa với đường kính đoạn hẹp trên CLVT là $6 \mathrm{~mm}$ (2 $\mathrm{TH})$ và $5 \mathrm{~mm}(1 \mathrm{TH})$, chiều dài đoạn hẹp là $20 \mathrm{~mm}(2 \mathrm{TH})$ và $15 \mathrm{~mm}(1 \mathrm{TH})$. NSPQ ghi nhận đường kính đoạn hẹp là $6 \mathrm{~mm}, 5,5 \mathrm{~mm}$ và $5 \mathrm{~mm}$, chiều dài đoạn hẹp là $20 \mathrm{~mm}, 15 \mathrm{~mm}$ và $10 \mathrm{~mm}$. Tất cả các BN này đều được phẫu thuật qua đường mở ngang cổ cắt bỏ đoan hẹp khí quản và khâu nối tận - tận. Kết quả giải phẫu bệnh đoạn hẹp cắt bỏ là mô lao xơ hóa, vôi hóa ổn định. Cả 3 BN này không cần điều trị lao sau mổ. Theo dõi sau 12 tháng (36 tháng -48 tháng), cả 3 BN đều có kết quả tốt không tái hẹp, lâm sàng không khó thở và không có tái phát lao.

Với nhóm BN hẹp phế quản gốc (PQG), chúng tôi ghi nhận tỉ lệ nữ giới chiếm đa số là $91,1 \%$ và độ tuổi trung bình là $30,7 \pm 10,1$ tuổi. Bệnh nhân nhập viện với triệu chứng thường gặp nhất là khó thở chiếm $64,4 \%$ các TH.

Về hình ảnh học của hẹp PQG trên CLVT, chúng tôi nhận thấy rằng đa phần hẹp toàn bộ PQG chiếm tỉ lệ là $60 \%$, trong đó với hẹp toàn bộ PQG phải chiếm 8/9 TH (88,9\%). Chiều dài đoạn hẹp trung bình là $26,2 \mathrm{~mm}$, đoạn hẹp PQG trái dài hơn so với PQG phải ( $27 \mathrm{~mm}$ so với $23,3 \mathrm{~mm}$ ). Đường kính lòng hẹp trung bình của $P Q G$ trên hình ảnh CLVT là $2 \mathrm{~mm}$. Trên NSPQ chỉ đo được đường kính lòng đoạn hẹp, trung bình $2,2 \mathrm{~mm}$. BN chỉ cắt nôi phế quản đởn thuần chiếm $40 \%$. Đa phần $B N$ được phẫu thuật $\mathrm{PQG}$ kèm theo cắt thuỳ phổi bị tổn thương chiếm $60 \%$. Thời gian dẫn lưu màng phổi trung bình là 4,7 ngày và thời gian nằm viện hậu phẫu là 10,7 ngày.

Bảng 1. Đặc điểm đoạn hẹp trong phẫu thuật

\begin{tabular}{|c|c|c|c|}
\hline Vị trí hẹp PQG & $\begin{array}{c}\text { Tất cả BN } \\
\mathbf{( N = 4 5 )}\end{array}$ & $\begin{array}{c}\text { Hẹp PQG phải } \\
\mathbf{( N = 9 )}\end{array}$ & $\begin{array}{c}\text { Hẹp PQG trái } \\
\mathbf{( N = 3 6 )}\end{array}$ \\
\hline Đâu PQ & $1(2,2 \%)$ & $1(11,1 \%)$ & $0(0,0 \%)$ \\
\hline Giữa PQ & $11(24,4 \%)$ & $0(0,0 \%)$ & $11(30,6 \%)$ \\
\hline Cuối PQ & $2(4,4 \%)$ & $0(0,0 \%)$ & $2(5,6 \%)$ \\
\hline Gần toàn bộ PQ & $31(68,9 \%)$ & $8(88,9 \%)$ & $23(63,9 \%)$ \\
\hline Đường kính lòng đoạn hẹp $(\mathrm{mm})$ & $1,8 \pm 1,7$ & $1,7 \pm 1,9$ & $1,9 \pm 1,7$ \\
\hline Chiều dài đoạn hẹp $(\mathrm{mm})$ & $27,3 \pm 7,4$ & $22,8 \pm 8,3$ & $28,5 \pm 6,8$ \\
\hline Kiếu phầu thuật & & & \\
\hline Cắt nối KPQ đơn thuần & $18(40,0 \%)$ & $3(33,3 \%)$ & $15(41,7 \%)$ \\
\hline Cắt thuỳ phối kèm cắt nối KPQ & $27(60,0 \%)$ & $6(66,7 \%)$ & $21(58,3 \%)$ \\
\hline
\end{tabular}


Chúng tôi ghi nhận đa phần BN không có biến chứng sau mổ chiếm $71,1 \%$. Biến chứng sau mổ thường gặp nhất là rò khí kéo dài chiếm 13,3\%. Đường kính miệng nối trung bình khi xuất viện là $6,6 \pm 1,5 \mathrm{~mm}$, khác biệt có nghĩa thống kề so trước mổ $\mathrm{p}<0,001$. Kết quả sớm sau phẩu thuật trên NSPQ, chúng tôi ghi nhận có 13/45 TH (chiếm 28,9\%) còn hẹp miệng nối.

Trong thời gian theo dõi, chúng tôi ghi nhận tại lần tái khám 1 tháng, có $8 \mathrm{BN}$ hẹp miệng nối nhưng chỉ $1 \mathrm{BN}$ hẹp miệng nối cần nhập viện để nong miệng nối, kết quả sau đó ổn định. Tại lần tái khám 3 tháng, $2 \mathrm{BN}$ hẹp miệng nối cần nhập viện. Trong đó, $1 \mathrm{BN}$ hẹp miệng nối $\mathrm{PQ}$ thùy dưới - $P Q$ gốc trái hoàn toàn nển phẫu thuật lại, $1 \mathrm{BN}$ hẹp miệng nối $\mathrm{PQ}$ trung gian - KQ nển NSPQ can thiệp nong $K P Q$. Tại lần tái khám 6 tháng, $1 \mathrm{BN}$ nhập viện để NSPQ can thiệp nong $\mathrm{PQ}$. Tại lần tái khám 12 tháng, $1 \mathrm{BN}$ tái hẹp hoàn miệng nối $P Q$ thùy dưới trái - Carina, nhập viện phẫu thuật lại. Như vậy, sau 12 tháng theo dõi, chúng tôi ghi nhận 2 TH mổ lại do hẹp hoàn toàn miệng nối và $2 \mathrm{TH}$ còn hẹp miệng nối sau nong. Tî lệ tái hẹp là 4/45 TH chiếm 8,9\%.

Bảng 2. Kêt quả sớm của phẫu thuật khi xuất viện

\begin{tabular}{|c|c|c|c|}
\hline & $\begin{array}{c}\text { Tất cả bệnh } \\
\text { nhân ( }\end{array}$ & $\begin{array}{c}\text { Hẹp PQG phải } \\
\text { (N=9) }\end{array}$ & $\begin{array}{c}\text { Hẹp PQG trái } \\
\mathbf{( N = 3 6 )}\end{array}$ \\
\hline Biến chứng sau mố & & & \\
\hline Không biến chứng & $32(71,1 \%)$ & $4(44,4 \%)$ & $28(77,8 \%)$ \\
\hline Chảy máu sau mố & $0(0,0 \%)$ & $0(0,0 \%)$ & $0(0,0 \%)$ \\
\hline Rò khí kéo dài & $6(13,3 \%)$ & $3(33,3 \%)$ & $3(8,3 \%)$ \\
\hline Rò KPQ & $0(0,0 \%)$ & $0(0,0 \%)$ & $0(0,0 \%)$ \\
\hline Viêm phối & $1(2,2 \%)$ & $0(0,0 \%)$ & $1(2,8 \%)$ \\
\hline Xẹp phối & $2(4,4 \%)$ & $1(11,1 \%)$ & $1(2,8 \%)$ \\
\hline Ho ra máu & $1(2,2 \%)$ & $0(0,0 \%)$ & $1(2,8 \%)$ \\
\hline Khàn tiếng & $2(4,4 \%)$ & $0(0,0 \%)$ & $2(5,6 \%)$ \\
\hline Biến chứng tim mạch & $2(4,4 \%)$ & $1(11,1 \%)$ & $1(2,8 \%)$ \\
\hline NSPQ & & & \\
\hline Thông thoáng, không hẹp & $32(71,1 \%)$ & $8(88,9 \%)$ & $24(66,7 \%)$ \\
\hline Hẹp nhưng không tắc nghẽn & $13(28,9 \%)$ & $1(11,1 \%)$ & $12(33,3 \%)$ \\
\hline Rò hay bung miệng nối & $0(0,0 \%)$ & $0(0,0 \%)$ & $0(0,0 \%)$ \\
\hline Dường kính miệng nối & $6,6 \pm 1,5 \mathrm{~mm}$ & $6,6 \pm 1,5 \mathrm{~mm}$ & $6,6 \pm 1,5 \mathrm{~mm}$ \\
\hline
\end{tabular}

Kết quả theo dõi sau 12 tháng, chúng tôi nhân thây tất cả các BN đều không khó thở và chỉ số Karnofsky sau mổ cải thiện rõ rệt so với trước mổ (98.0 \pm 4.6 so với $73.8 \pm 6.5)$ khác biệt có ý nghĩa thống kê, $p<0,001$. Các BN này đều được chụp CLVT ngực dựng hình cây KPQ và NSPQ kiểm tra, ghi nhận đường kính miệng nối tăng đáng kể so trước mổ khác biệt có ý nghĩa thống kê, $p<0,001$.

Bảng 3. Kêt quả theo dôi sau 12 tháng

\begin{tabular}{|c|c|c|c|}
\hline & $\begin{array}{c}\text { Trước mổ } \\
(\mathrm{N}=45)\end{array}$ & $\begin{array}{c}\text { Sau mố } 12 \\
\text { tháng } \\
(\mathrm{N}=45)\end{array}$ & $\begin{array}{c}\text { Giá trị } \\
\text { p }\end{array}$ \\
\hline \multicolumn{3}{|c|}{ Đường kính hẹp/NSPQ } & $<0.001$ \\
\hline & $2,2 \pm 1,9 \mathrm{~mm}$ & $9,1 \pm 2,6 \mathrm{~mm}$ & \\
\hline \multicolumn{3}{|c|}{ Mức độ hẹp theo Myer - Cotton/ NSPC } & $<0.001$ \\
\hline 1 & $0(0.0 \%)$ & $36(81.8 \%)$ & \\
\hline 2 & $5(11.9 \%)$ & $5(11.4 \%)$ & \\
\hline 3 & $22(52.4 \%)$ & $1(2.3 \%)$ & \\
\hline 4 & $15(35.7 \%)$ & $2(4.5 \%)$ & \\
\hline \multicolumn{3}{|c|}{ Đường kính hẹp/CLVT } & $<0.001$ \\
\hline & $2,0 \pm 1,9$ & $9,7 \pm 3,1 \mathrm{~mm}$ & \\
\hline \multicolumn{3}{|c|}{ Mức độ hẹp theo Myer-Cotton/ CLVI } & $<0.001$ \\
\hline 1 & $0(0.0 \%)$ & $41(91.1 \%)$ & \\
\hline 2 & $3(6.7 \%)$ & $2(4.4 \%)$ & \\
\hline 3 & $23(51.1 \%)$ & $0(0.0 \%)$ & \\
\hline 4 & $19(42.2 \%)$ & $2(4.4 \%)$ & \\
\hline
\end{tabular}

\section{BÀN LUÂ̂N}

4.1. Kết quả sớm và biến chứng sau mổ. Kết qủa không có tử vong và tai biến trong và sau mổ, tuy nhiên $13 / 45$ BN $(28,9 \%)$ có biến chứng sau mổ, trong đó rò khí kéo dài hơn 5 ngày chiếm tỉ lệ cao nhất $13,3 \%$, nguyên nhân từ nhu mô phổi ở những $\mathrm{TH}$ cắt thùy kèm tạo hình $\mathrm{KPQ}$. Trong đó có $1 \mathrm{TH}$ chúng tôi cần phải làm dính bằng Betadin $10 \%$ và rút ông dẫn lưu ngày thứ 11 . Nghiên cứu của chúng tôi cũng tương tự tác giả Palade $11,7 \%[3]$. Thời gian nằm viện sau mổ của chúng tôi trung bình 10,84 ngày (6-18 ngày) dài hơn so với báo cáo Ragusa là 9 ngày [4], nhưng ngắn hơn so với Tsukioka là 14 ngày ( $9-27$ ngày) [5].

Trong khi đó, Kato có 2 TH (5,6\%) tử vong, 1 TH tử vong do phù phổi ngày đâu sau mổ và 1 TH tử vong sau 4 tháng do chảy máu nhiều trong khi đang NSPQ cắt đốt mô hạt miệng nối 
[6]. Tác giả Kikuchi cũng ghi nhận 1 TH (2,6\%) tử vong do phù phổi cấp [7]. Tác giả Lei phẫu thuật $25 \mathrm{TH}$ hẹ KPQ do lao thì không có tử vong, nhưng biển chứng sau mổ gồm xẹp phổi 2 TH (8\%), rung nhĩ 1 TH (4\%), mủ màng phổi 2 $\mathrm{TH}(8 \%)$ và nhiễm trùng vết mổ $1 \mathrm{TH}(4 \%)$ [8]. Các biến chứng sớm sau phẫu thuật thường bao gồm xẹp phổi, viêm phổi, suy hô hấp và rò $P Q$ khoang màng phổi. Đôi khi những biến chứng này có thể liên quan lẫn nhau và có thể xuất hiện theo trình tự. Ví dụ, xẹp phổi có thể gây viểm phổi, cuối cùng dẫn đến suy hô hấp và kết quả là nhiễm trùng phổi trầm trọng hơn. Hơn nữa, nhiễm trùng khoang màng phổi là một trong những yếu tố nguy cơ cao của bệnh rò PQ khoang màng phổi. Để hạ chế xep phổi sau mổ, các $\mathrm{BN}$ mở ngực trong nhóm nghiên cứu của chúng tôi đều được gây tê ngoài màng cứng, điều này giúp giảm đau tốt sau mổ, BN có thể ngồi dậy sớm tập hít thở dưới sự hướng dẫn của kỹ thuật viên vật lý trị liệu. Đồng thời, tất cả các BN sau phẫu thuật 1 - 3ngày đều được tiến hành NSPQ ống mềm để hút đờm máu và đánh giá miệng nối để can thiệp kịp thời.

4.2. Kết quả trung hạn sau mổ. Kết quả toàn trạng $\mathrm{BN}$ theo chỉ số Karnofsky sau mổ (12 tháng) cho thấy $100 \%$ toàn trạng tốt (từ 80 100 điểm), BN có thể hoạt động và làm việc bình thường, không có nhu cầu chăm sóc đặc biệt.

Tác giả Tsukioka đánh giá thể trạng BN dựa theo thang điểm Performance Status và độ khó thở theo thang điểm Hugh Jones classification cho thây tất cả $12 \mathrm{BN}$ sau mổ tạo hình $\mathrm{KPQ}$ do lao đều tăng so trước mổ, có ý nghĩa thống kê $(p<0,001)[5]$.

Tình trạng lâm sàng sau mổ

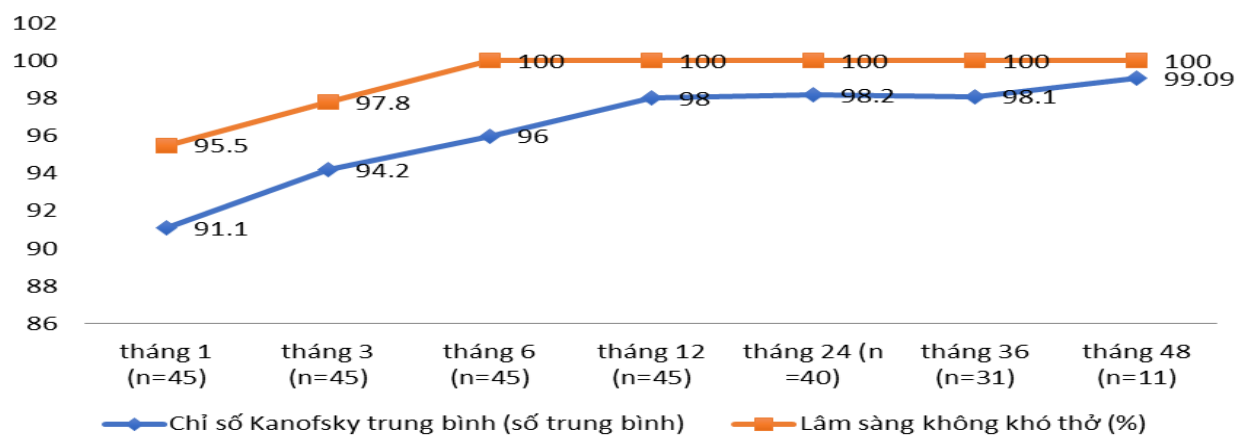

Biểu đồ 1. Thay đổi chỉ số Kanofsky và mức khó thở sau mồ

So với trước phẫu thuật, ngyuy cơ khó thở giảm dần theo thời gian sau phẫu thuật. Kết quả sau mổ từ 12 tháng cho thấy $100 \%$ BN không khó thở.

Tóm lại, kết quả phẫu thuật tạo hình $45 \mathrm{BN}$ hẹp KPQ do lao theo dõi từ $12-48$ tháng, chúng tôi ghi nhận 2 BN hẹp nhẹ miệng nối và 2 BN hẹp hoàn toàn miệng nối phải phẫu thuật lại, không có TH nào lao tái phát.

\section{KẾT LUÂN}

Phẫu thuật hẹp khí phế quản do lao có kết quả sớm tốt và không có tử vong. Tỉ lệ biến chứng sớm của phẫu thuật thấp và chỉ cần điều trị nội khoa đơn thuần. Kết quả trung hạn của phẫu thuật khả quan và không có biến chứng muộn.

\section{TÀI LIỆU THAM KHẢO}

1. Low, S.Y., A. Hsu, and P. Eng, Interventional bronchoscopy for tuberculous tracheobronchial stenosis. Eur Respir J, 2004. 24(3): p. 345-7
2. Xue, Q.W., N; Xue, X; Wang, J, endobronchial tuberculosis: an overview. European Journal of clinical Microbiology \& Infectious diseases, 2011. 30(9): p. 1039-1044.

3. Palade, E., H. Holdt, and B. Passlick, Bronchus anastomosis after sleeve resection for lung cancer: does the suture technique have an impact on postoperative complication rate? Interact Cardiovasc Thorac Surg, 2015. 20(6): p. 798-804.

4. Ragusa, M., et al., Left main bronchus resection and reconstruction. A single institution experience. J Cardiothorac Surg, 2012. 7: p. 29.

5. Tsukioka, T., et al., Surgical reconstruction for tuberculous airway stenosis: management for patients with concomitant tracheal malacia. Gen Thorac Cardiovasc Surg, 2015. 63(7): p. 379-85.

6. Kato, R., et al., Bronchoplastic procedures for tuberculous bronchial stenosis. J Thorac Cardiovasc Surg, 1993. 106(6): p. 1118-21

7. Kikuchi, K. and K. Kobayashi, [Surgical treatment for tracheobronchial tuberculosis]. Kekkaku, 1997. 72(1): p. 43-8

8. Lei, Y., et al., Analysis of the surgical treatment of endobronchial tuberculosis (EBTB). Surg Today, 2014. 44(8): p. 1434-7 